\title{
Helical self-similarity of tip vortex cores
}

Okulov, Valery; Kabardin, Ivan K.; Mikkelsen, Robert Flemming; Naumov, Igor; Sørensen, Jens Nørkær

Published in:

Journal of Fluid Mechanics

Link to article, DOI:

$10.1017 / \mathrm{jfm} .2018 .850$

Publication date:

2019

Document Version

Peer reviewed version

Link back to DTU Orbit

Citation (APA):

Okulov, V., Kabardin, I. K., Mikkelsen, R. F., Naumov, I., \& Sørensen, J. N. (2019). Helical self-similarity of tip vortex cores. Journal of Fluid Mechanics, 859, 1084-1097. https://doi.org/10.1017/jfm.2018.850

\section{General rights}

Copyright and moral rights for the publications made accessible in the public portal are retained by the authors and/or other copyright owners and it is a condition of accessing publications that users recognise and abide by the legal requirements associated with these rights.

- Users may download and print one copy of any publication from the public portal for the purpose of private study or research.

- You may not further distribute the material or use it for any profit-making activity or commercial gain

- You may freely distribute the URL identifying the publication in the public portal

If you believe that this document breaches copyright please contact us providing details, and we will remove access to the work immediately and investigate your claim 


\section{Journal of Fluid Mechanics}

\section{Date of delivery: November 09, 2018}

$\begin{array}{llll} & & & \\ \text { Journal and vol/article ref: } & \mathbf{f l m} \quad \mathbf{1 8 0 8 5 0}\end{array}$

Number of pages (not including this page): 14

This proof is sent to you on behalf of Cambridge University Press.

Authors are strongly advised to read these proofs thoroughly because any errors missed may appear in the final published paper. This will be your ONLY chance to correct your proof. Once published, either online or in print, no further changes can be made.

Please return marked proofs within 7 days of receipt to: JFMProofing@sunrise-setting.co.uk

\section{THIS PDF IS FOR PROOF CHECKING PURPOSES ONLY. IT SHOULD NOT BE DISTRIBUTED} TO THIRD PARTIES AND MAY NOT REPRESENT THE FINAL VERSION.

\section{CORRECTING AND RETURNING YOUR PROOFS - PLEASE READ}

The proofs show changes made to the MAIN TEXT by the Copy Editor. Inserted text is shown in red. Locations of deleted text are indicated with a yellow rectangle/grey arrow. When viewed using the free Adobe Reader software, deleted text becomes visible when the pointer hovers over the yellow rectangle. (This does not happen with other PDF viewers.) PLEASE DO NOT USE 'Mac OS X 10.9.3 Quartz PDFContext' to save the pdf, it corrupts the proofs (known bug).

Do not attempt to edit the body of the text within the pdf in any way.

PLEASE CHECK CAREFULLY maths formulae (changes cannot be tracked) and figures/ captions (all are relabelled by the typesetter and should be checked against your originals).

\section{HOW TO RETURN YOUR PROOFS}

\section{PLEASE DO NOT SEND LISTS - ALL CORRECTIONS AND NOTES MUST BE MARKED} DIRECTLY ON THE PDF PROOFS AND BE CLEAR AND SUCCINCT. Emails are not passed on with the PDF. Please avoid lists, dialogue and long explanations.

You can mark up proofs either on screen using the enabled electronic editing tools or by hand on the hardcopy.

Marking up electronically. All proofs are enabled to allow electronic annotation in the free Adobe Reader software. Using your cursor select the text for correction, right click and use the most appropriate single tool (i.e. 'Replace', 'Cross out' or 'Add note to text'), to insert place the cursor then go to Tools/Comment\&mark up/Text edits/Insert text at cursor. Please do not use the 'Sticky note' function its placement is not precise enough. 'Show comments' allows all marks to be clearly seen by the typesetter, please do not emphasise your marks in any way. Please return the file as an attachment via email.

Marking up by hand. Please use the proof correction symbols indicated keeping marks clear and concise. Scanned proofs can be returned via email. 


\section{Journal of Fluid Mechanics}

Offprints: If you wish to order paper offprints, this should be done at the same time as returning your proofs. Please click on the link below to download an order form. Please follow the instructions on the form carefully and complete it as an electronic form if possible.

https://www.cambridge.org/core/services/aop-file-manager/file/5aec57c3f6e65274069f35bc

If you have no corrections to make please inform the Production Team by email - JFMProofing@sunrisesetting.co.uk

Postal address - to be used only where other options are not possible

Journal of Fluid Mechanics - Mrs A. R. James

Cambridge University Press

Edinburgh Building

Shaftesbury Road

Cambridge CB2 8RU, UK Tel: $+44(0) 1223326061$

For further infomation about Journals Production please consult our FAQs at http://journals.cambridge. org/production_faqs

Please note:

- The proof is sent to you for correction of typographical errors only. Revision of the substance of the text is not permitted, unless discussed with the editor of the journal. Only one set of corrections are permitted.

- Please answer carefully any author queries.

- Corrections which do NOT follow journal style will not be accepted.

- A new copy of a figure must be provided if correction of anything other than a typographical error introduced by the typesetter is required.

- If you have problems with the file please contact

JFMproduction@cambridge.org

Please note that this pdf is for proof checking purposes only. It should not be distributed to third parties and may not represent the final published version.

Important: you must return any forms included with your proof.

\section{Please do not reply to this email}

NOTE - for further information about Journals Production please consult our FAQs at http://journals.cambridge.org/production_faqs 


\section{Proof correction symbols}

\begin{tabular}{|c|c|c|}
\hline $\begin{array}{l}\text { Correction } \\
\text { required }\end{array}$ & $\begin{array}{l}\text { Marginal } \\
\text { mark }\end{array}$ & $\begin{array}{l}\text { Corresponding } \\
\text { mark in text }\end{array}$ \\
\hline $\begin{array}{l}\text { Insert new } \\
\text { material }\end{array}$ & $\begin{array}{l}\text { Inserted } \\
\text { material, } \\
\text { followed by } \\
\text { caret, } L\end{array}$ & \\
\hline Delete & & $\begin{array}{l}\text { (Cross out what is } \\
\text { not wanted) }\end{array}$ \\
\hline $\begin{array}{l}\text { Substitute } \\
\text { new material } \\
\text { for something } \\
\text { typeset }\end{array}$ & $\begin{array}{l}\text { Write new } \\
\text { material } \\
\text { followed } \\
\text { by }\end{array}$ & $\begin{array}{l}\text { (Cross out material } \\
\text { to be replaced) }\end{array}$ \\
\hline $\begin{array}{l}\text { Leave as } \\
\text { printed }\end{array}$ & & $\begin{array}{l}\ldots . . . \text { under material } \\
\text { to remain }\end{array}$ \\
\hline Insert space & & $\begin{array}{l}\lambda_{\text {where space is }} \\
\text { required }\end{array}$ \\
\hline $\begin{array}{l}\text { Take out space } \\
\text { (close up) }\end{array}$ & & $\begin{array}{l}\mathcal{D} \text { around material } \\
\text { to be closed up }\end{array}$ \\
\hline Insert hyphen & & $\begin{array}{l}\text { where hyphen } \\
\text { is required }\end{array}$ \\
\hline $\begin{array}{l}\text { Change } \\
\text { letter(s) to } \\
\text { capital(s) }\end{array}$ & & $\sum_{\text {required }}$ under letter(s) \\
\hline $\begin{array}{l}\text { Change } \\
\text { letter(s) to } \\
\text { small capital(s) }\end{array}$ & & $\rightleftharpoons_{\text {required }}$ under letter(s) \\
\hline $\begin{array}{l}\text { Change to } \\
\text { small letter(s) }\end{array}$ & & $\begin{array}{l}\text { (Encircle required } \\
\text { letter(s)) }\end{array}$ \\
\hline $\begin{array}{l}\text { Change to } \\
\text { bold type }\end{array}$ & & to be altered \\
\hline $\begin{array}{l}\text { Change to } \\
\text { italic type }\end{array}$ & & _ to be altered \\
\hline $\begin{array}{l}\text { Begin a new } \\
\text { paragraph }\end{array}$ & & $\begin{array}{l}{[\text { before first }} \\
\text { word of new } \\
\text { paragraph }\end{array}$ \\
\hline
\end{tabular}

\begin{tabular}{|c|c|c|}
\hline $\begin{array}{l}\text { Correction } \\
\text { required }\end{array}$ & $\begin{array}{l}\text { Marginal } \\
\text { mark }\end{array}$ & $\begin{array}{l}\text { Corresponding } \\
\text { mark in text }\end{array}$ \\
\hline $\begin{array}{l}\text { No new } \\
\text { paragraph }\end{array}$ & & D between \\
\hline $\begin{array}{l}\text { Inferior } \\
\text { (subscript) } \\
\text { letter, e.g. } x\end{array}$ & & $\begin{array}{l}\text { if to be } \\
\text { inserted; cross } \\
\text { out incorrect } \\
\text { letter if a } \\
\text { replacement }\end{array}$ \\
\hline $\begin{array}{l}\text { Superior } \\
\text { (superscript) } \\
\text { letter, e.g.p }\end{array}$ & & $\begin{array}{l}\text { if to be } \\
\text { inserted; cross } \\
\text { out incorrect } \\
\text { letter if a } \\
\text { replacement }\end{array}$ \\
\hline $\begin{array}{l}\text { Transpose } \\
\text { letters or } \\
\text { words }\end{array}$ & & $\begin{array}{l}7 \text { between } \\
\text { letters or words }\end{array}$ \\
\hline $\begin{array}{l}\text { Indicate } \\
\text { letters set } \\
\text { upside-down }\end{array}$ & & $\begin{array}{l}\text { (Encircle letters } \\
\text { to be altered) }\end{array}$ \\
\hline $\begin{array}{l}\text { Broken letter; } \\
\text { replace by } \\
\text { similar but } \\
\text { undamaged } \\
\text { character }\end{array}$ & & $\begin{array}{l}\text { (Encircle letters } \\
\text { to be altered) }\end{array}$ \\
\hline $\begin{array}{l}\text { Insert } \\
\text { parentheses }\end{array}$ & & $\begin{array}{l}\text { Lhwhere } \\
\text { parentheses } \\
\text { required }\end{array}$ \\
\hline $\begin{array}{l}\text { Insert square } \\
\text { brackets }\end{array}$ & & $\begin{array}{l}\angle L \text { where } \\
\text { square brackets } \\
\text { required }\end{array}$ \\
\hline $\begin{array}{l}\text { Insert } \\
\text { apostrophe }\end{array}$ & & $\begin{array}{l}\text { where } \\
\text { apostrophe } \\
\text { required }\end{array}$ \\
\hline $\begin{array}{l}\text { Insert } \\
\text { quotation } \\
\text { marks }\end{array}$ & & $\begin{array}{l}\text { Lh where } \\
\text { quotation } \\
\text { marks required }\end{array}$ \\
\hline
\end{tabular}




\title{
Helical self-similarity of tip vortex cores
}

\author{
Valery L. Okulov ${ }^{1,2, \dagger}$, Ivan K. Kabardin ${ }^{2}$, Robert F. Mikkelsen ${ }^{1}$, \\ Igor V. Naumov ${ }^{2}$ and Jens N. Sørensen ${ }^{1}$ \\ ${ }^{1}$ Department of Wind Energy, Technical University of Denmark, 2800 Lyngby, Denmark \\ ${ }^{2}$ Kutateladze Institute of Thermophysics, SB RAS, Novosibirsk 630090, Russia
}

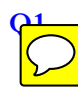

Q2

(Received 11 April 2018; revised 21 September 2018; accepted 17 October 2018)

The present work investigates local flow structures and the downstream evolution of the core of helical tip vortices generated by a three-bladed rotor. Earlier experimental studies have shown that the core of a helical tip vortex exhibits a local helical symmetry with a simple relation between the axial and azimuthal velocities. In the present study, a self-similarity scaling argument further describes the downstream development of the vortex core. Self-similarity has up to now only been investigated for longitudinal vortices and it is the first time that helical vortices have become the subject of such an analysis. Combining symmetry arguments from previous studies on helical vortices with novel experiments and knowledge regarding the self-similarity evolution of the core of longitudinal vortices, a new model describing what is referred to as 'helical self-similarity' is proposed. The generality of the model is verified and supported by experimental data. The proposed model is important for fundamental understanding of the behaviour of helical vortices, with a range of applications in both industry and nature. Examples of this are tip vortices behind aerodynamic devices, such as vortex generators, and fixed and rotary aircraft, and in combustion chambers and cyclone separators.

Key words: aerodynamics, flow-structure interactions, vortex flows, vortex dynamics, wakes, wakes/jets

\section{Introduction}

Helical vortices appear both in nature and in connection with various fluid dynamic applications, and many flow visualizations have shown that the flow behaviour in the near wake of rotors essentially is determined by concentrated helical vortices. This includes vortices emanating from the blade tips of wind turbines (Vermeer, Sørensen \& Crespo 2003), helicopters (Leishman 2006) and propellers (Felli \& Camussi 2011; Sørensen 2011). Assuming ideally that the shapes of the helical tip vortices are kept unchanged when progressing into the wake, it is possible to derive analytical solutions describing the flow field (Okulov \& Sørensen 2010; Okulov, Sørensen \& Wood 2015b). These vortex solutions together with a simplification of the rotor as an actuator disc enabled appropriate approximations for blade design, leading to classical design proposals (see Van Kuik, Sørensen \& Okulov 2015 or Sørensen et al. 2016).

$\dagger$ Email address for correspondence: vaok@dtu.dk 
Further downstream in the wake, however, the helical vortices become unstable and break down into turbulence (Felli \& Camussi 2011; Quaranta, Bolnot \& Leweke 2015; Sarmast et al. 2015). To understand and predict the stability properties of helical vortices and their subsequent transition to turbulence, it is important to be able to describe the flow structures of the undisturbed vortices (Sørensen et al. 2014).

Widnall (1972) and Gupta \& Loewy (1974) were the first to utilize a Rankine vortex model (constant-vorticity core) as a basis for studying the stability of helical vortices. Fukumoto \& Miyazaki (1991) later extended this work by including an axial flow component along the vortex core. Recently, Quaranta et al. (2015) experimentally discovered and improved the models by introducing a more realistic Gaussian vorticity distribution with an additional axial flow in the core. The proposed scaling behaviour and the concept of helical self-similarity including both the axial and the azimuthal velocity profiles in the helical vortex core are expected to provide a more correct basis for future studies on vortex instability.

A main problem associated with near-wake studies is to understand the downstream evolution of the tip vortex core, where the continuous growth in the vortex core strongly affects the global vortex stability. A classic example of this is the self-similar temporal growth of the Lamb-Oseen vortex (Saffman 1992), for which a time-spatial relation for the downstream development is established using a molecular diffusion model. Ali \& Abid (2014) paid particular attention to the swirling form of the helical tip vortex to investigate the degree of resemblance between the helical vortex core and the Lamb-Oseen vortex. For this purpose, they applied a numerical solution of the Navier-Stokes equations for different low Reynolds numbers, using the actuator line approximation (Sørensen \& Shen 2002), to estimate the vortex core evolution due to molecular diffusion as a function of vortex age. The evolution of velocity and vorticity in the core of the helical tip vortex, generated by a single-bladed rotor, was compared to the solution of the Lamb-Oseen vortex assuming a molecular diffusive expansion of the rectilinear vortex core. The authors (Ali \& Abid 2014) used appropriate similarity variables and scaling to remove the local and global non-axisymmetric effect on the helical vortex topology, and reached a good agreement with the axisymmetric solution of the Lamb-Oseen vortex. Ultimately, the numerical investigation showed that the diffusive evolution of the helical vortex core with good accuracy coincides with the molecular diffusive evolution of the Lamb-Oseen vortex. However, this process, depending only on kinematic viscosity, is very slow and disagrees with observations of practical swirling flows, where a significantly greater expansion of the vortex core takes place due to turbulent diffusion. Nevertheless, Ali \& Abid (2014) demonstrated the possibility of employing special variables and scaling to remove the local and global non-axisymmetric effects in order to compare vortex cores of helical and rectilinear vortices.

Recently, considering the evolution of the tip vortex core in different cross-sections behind an immobile vortex generator, and by scaling the local radius of the vortex core and the local helical pitch of the vortex lines filling the core, Velte, Hansen \& Okulov (2009) found a complete correspondence between the local axial and azimuthal velocity profiles. This correlation, referred to as 'local helical symmetry', was originally introduced by Alekseenko, Kuibin \& Okulov (2007) to describe main parameters of swirling flows.

The current study is based on experimental observations from current and previous studies of tip vortices behind a three-bladed rotor (Naumov et al. 2012, 2014). Rotating blades generate helical vortices at the tip of the blades (figure $1 a$ ). In global terms, the helical system is described by a vortex pitch $H$ and a tip vortex 
(a)

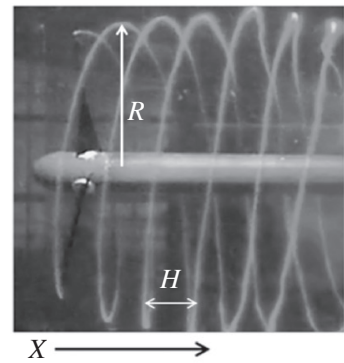

(b)

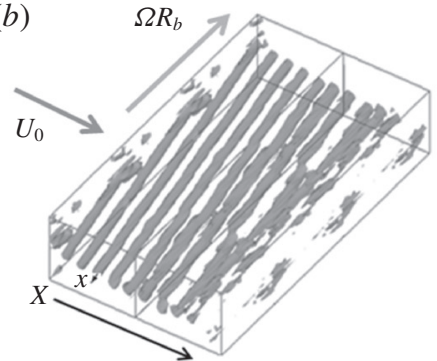

(c)

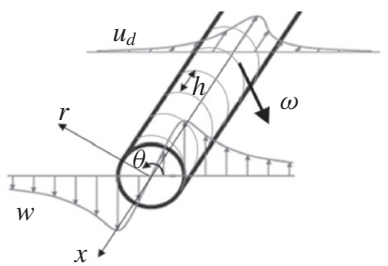

COL-www

FIGURE 1. (Colour online) Visualization of tip vortices behind a rotor $(a)$, horizontal scanning of tip vortices $(b)$ and local coordinate system $(r, \theta, x)$ of a single tip vortex $(c)$.
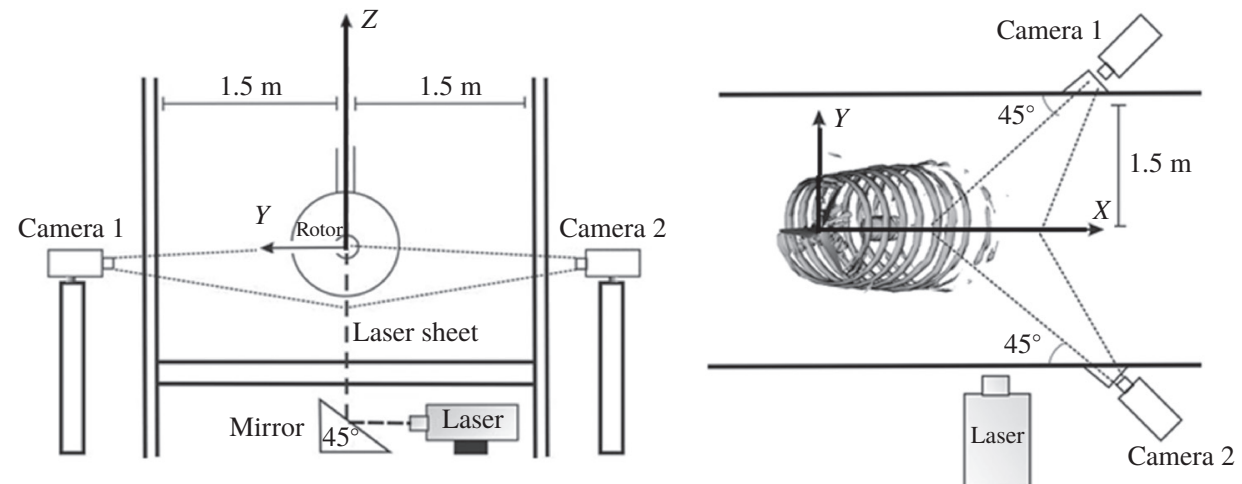

COL-www

FIgURE 2. (Colour online) Sketch of PIV measurements in the two cross-sections of the flume and definition of the global coordinate system $(X, Y, Z)$.

radius $R$. The local coordinates $(x, r, \theta)$ are introduced to study the development of the individual vortex core (see figure $1 b, c$ ). Note that $u_{d}$ in the figure denotes the deficit velocity. The objective is to deduce the possible existence of a general relation between the local axial velocity $u$ and the local azimuthal velocity $w$ in all cross-sections of a tip vortex, or, in other words, to investigate the possibility of self-similar behaviour along the vortex axis $x$. This procedure of combining local-scale similarity with the downstream development of the vortex core will in the following be referred to as 'helical self-similarity'.

\section{Experimental set-up and method}

\subsection{Experimental set-up and measurement technique}

The basis for the work is a series of experiments of tip vortices generated on a model of a horizontal axis wind turbine. The experiments were carried out in a water flume of length $35 \mathrm{~m}$ and width $3 \mathrm{~m}$, and a water level of about $0.9 \mathrm{~m}$ (figure 2). The temperature of the water was $20^{\circ} \mathrm{C}$. The test section of the flume is equipped with transparent walls at a distance of $20 \mathrm{~m}$ from the flume inlet. The free-flow velocity in the test section of the flume was about $U_{0}=0.6 \mathrm{~m} \mathrm{~s}^{-1}$ with a water flow rate of $1.5 \mathrm{~m}^{3} \mathrm{~s}^{-1}$. The allowed deviations in the flow rate were less than $2 \%$. The small boundary layer thickness $(\approx 0.2 \mathrm{~m})$ and the slight level of turbulent pulsations 
$(\sim 2.5 \%)$ for the undisturbed flow provide a nearly uniform incoming flow in the test area in the middle of the flume, according to previous data (Okulov et al. 2014).

The three-bladed model rotor has a diameter of $0.376 \mathrm{~m}$, and is equipped with blades of length $159 \mathrm{~mm}$ consisting of SD7003 airfoil sections (Selig et al. 1995). The shape and pitch setting of the blades were determined using the aerodynamic design theory of Glauert (Okulov et al. 2015 QDpr optimum operating conditions with a constant design lift coefficient along the span $\left(C_{L}=0.8\right)$. The rotor was designed to operate optimally at a tip speed ratio $\lambda=5$, where $\lambda=\Omega R_{b} / U_{0}$, with $\Omega$ being the rotor angular velocity, $R_{b}$ the rotor radius and $U_{0}$ the initial velocity in the flume. The Reynolds number for all experiments was about 20000 , calculated as $R e=\rho b \Omega R_{b} / \mu$. Here $b=0.1$ is the chord length of the blade, and $\rho$ and $\mu$ are the density and dynamic viscosity of the working fluid (tap water), respectively.

The rotor is located at a height of $0.5 \mathrm{~m}$ from the flume bottom and at a distance of $1.5 \mathrm{~m}$ from the flume walls (see figure 2), thus avoiding the influence of the boundary layer, whose thickness is less $20 \mathrm{~cm}$ from the bottom and the walls of the flume. The ratio between the rotor area $\left(0.111 \mathrm{~m}^{2}\right)$ and the area of the flume cross-section $\left(3 \mathrm{~m}^{2}\right)$ is $3.7 \%$. Therefore, blockage effects are very small and no corrections are made. The rotor was driven by a JVL Industri Elektronik MAC140 servo motor, which was operated at a constant rotational speed within $1.5 \%$ accuracy. The torque was transmitted by the external gear at the axis of each rotor.

The global coordinate system is defined in figure 2 . The origin of the coordinate system is chosen as the cross-section of the rotor axis and the rotor plane, with $X$ pointing in the axial direction, $Y$ in the wall-normal direction and $Z$ in the spanwise direction (see figure 2). The velocity components in $O X, O Y$ and $O Z$ directions are denoted $U, V$ and $W$, respectively. The local coordinates $(x, r, \theta)$ were introduced to study the development of the individual vortex core (see figure $1 b, c$ ), where $x$ follows a central line of the tip vortices, and $h$ denotes the internal tip vortex pitch with $l=$ $h / 2 \pi$. The tip vortices expand in the wake from the rotor blades to a radius $R \approx$ $1.22 R_{b}$ (Okulov et al. 2014). The local velocity field is given as $(u, v, w)$, with $u_{0}=$ $u(x, 0)$ denoting the vortex centre, and $u_{d}(x, r)=\left(u(x, r)-u_{0}(x)\right)$ defining the deficit velocity.

The flow field was measured using a Dantec stereoscopic particle image velocimetry (PIV) system, which gives all three velocity components $(U, V, W)$ throughout the window of the light sheet. An Nd:YAG laser was used as light source with the following characteristics: $120 \mathrm{~mJ}$ of energy in a single pulse, a wavelength of $532 \mathrm{~nm}$ and an operational frequency of $15 \mathrm{~Hz}$. A $2 \mathrm{~mm}$ thick vertical light sheet was sent into the channel from the bottom in the same plane as the rotor axis (figure 2). The processing of the images resulted in three downstream windows to yield the local velocity field. The final size of the full three-dimensional velocity field for investigating the helical tip vortex was $1.03 \mathrm{~m} \times 0.29 \mathrm{~m}$. The images in the measuring windows were recorded by two Dantec HiSense II cameras with $1344 \times 1024$ pixel resolution. The cameras were placed perpendicularly to each other on the different sides of the flume with an angle of $45^{\circ}$ to the walls (figure 2). Water-filled optical prisms were installed between the cameras, and the focus plane was adjusted using Scheimpflug adapters. The three-dimensional velocity field in each testing window was calculated using Dantec Dynamic Studio 2.21. The stereoscopic PIV system was calibrated using a target with a well-defined dot pattern which was translated and registered by the cameras in a number of well-defined positions at the light sheet. The measuring error of stereoscopic PIV velocity measurements was at the level of $3 \%-5 \%$. 


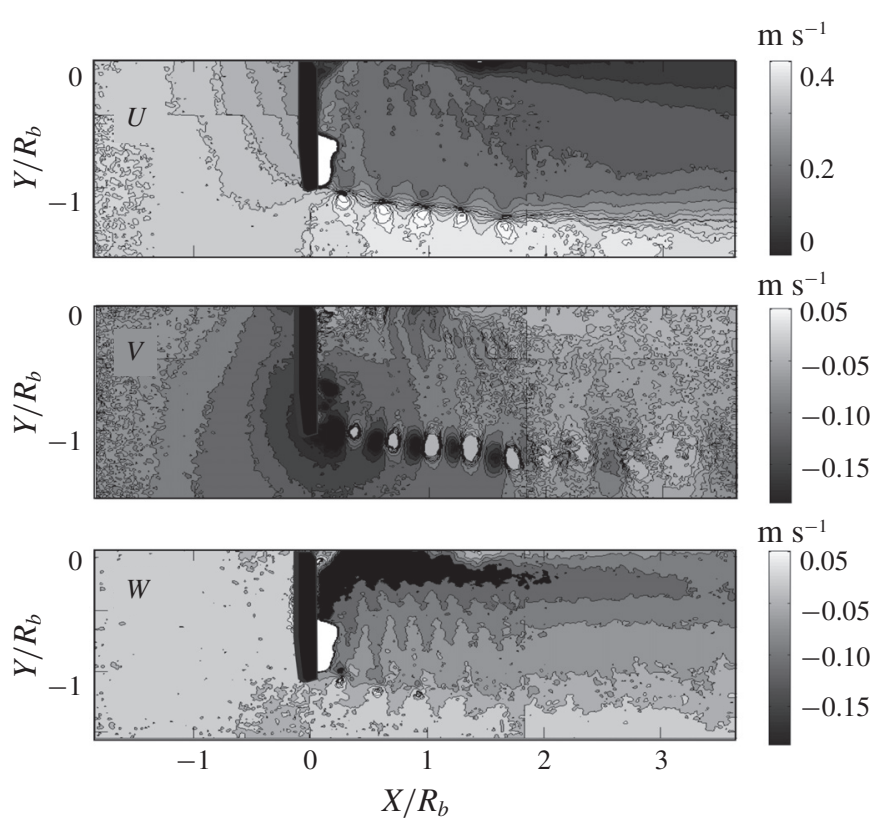

FIGURE 3. The iso-contours of the global axial $(U)$, radial $(V)$ and azimuthal $(W)$ velocities at $\lambda=5$.

The synchronized velocity field in each window was obtained by phase averaging of 200 PIV velocity realizations, which were recorded in the moment of a triggered signal by a light pulse for each complete rotation of the rotor. An angular encoder (LIKA ASR58) with angular resolution of $0.1^{\circ}$, installed on the rotor hub, triggered a pulse when one of the blades passed through the light sheet. The stochastic errors vanish by this phase averaging. Moreover, this approach eliminates the drifting error due to non-stationary flow regimes. The time interval between consecutive PIV images was based on the frequency of the rotor rotation, which for $\lambda=5$ was $T=(1 / 2.18)$ s.

\subsection{Vortex core determination}

Figure 3 shows the phase-averaged distributions of the axial $(U)$, radial $(V)$ and azimuthal $(W)$ velocity components of the flow for $\lambda=5$. The angles of the blade rotation from which the synchronization was made in the experiments were verified in the range $\alpha=0-105^{\circ}$, with steps of $15^{\circ}$. The vorticity field was calculated from the velocity field in all cross-sections (figures 3 and 4). The plots demonstrate that the tip vortices appear as regular vortex structures with clear cores. The vortex cores are destroyed at a distance in the range between $1.8 R$ and $3.6 R$ due to their mutual interaction. The vorticity cross-section with the clearest vortex cores was used to determine the c्रentres of the tip vortices $\left(Y_{c}, Z_{c}\right)$ in the PIV plane. The centres of the tip vortices were determined from an algorithm based on the centre of mass. The vortex core is described in a rectangular domain, $A$, defined as $Y-Y_{c} \in[-h / 2, h / 2]$ and $Z-Z_{c} \in\left[-R_{b} / 2, R_{b} / 2\right]$. The circulation $\Gamma$ of the vortex core is determined by integration of the vorticity:

$$
\Gamma=\int_{A} \omega_{x} \mathrm{~d} A .
$$




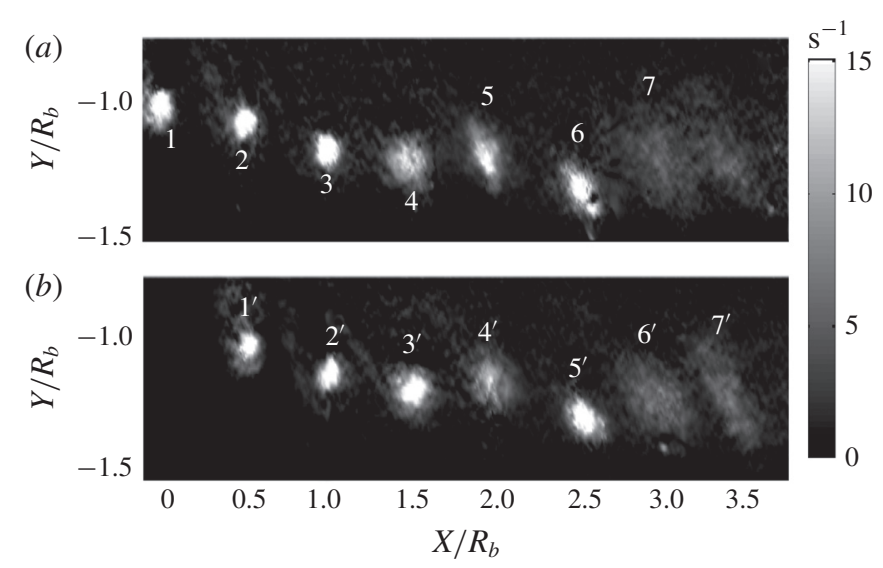

FIGURE 4. The vorticity maps of tip vortex cross-sections for the rotor synchronizations at an angle of $(a) 0^{\circ}$ and $(b) 105^{\circ}$. Examples of the local coordinates and numbering of the vortex cross-sections.

The images of the tip vortex cores along the wake were from left to right numbered 1 to 9 . Hence, the vortex cores $1,4,7$ and $1^{\prime}, 4^{\prime}, 7^{\prime}$; cores $2,5,8$ and $2^{\prime}, 5^{\prime}, 8^{\prime}$; cores 3,6, 9 and $3^{\prime}, 6^{\prime}, 9^{\prime}$ correspond to the cross-section of the tip vortices behind the first, second and third blades, respectively. The vorticity plots also show that blurring of the vortex core takes place. The first six images of the core have a strong concentration of vorticity and are approximately located at equal distances from each other, whereas the vorticity concentrations of c्रores 7,8 and 9 are seen to be less dense and the cores are displaced further from each other. Based on the observations, the development of the helical vortex cores will be analysed in the next section.

\section{Helical self-similarity of the vortex cores}

Self-similarity occurs when the velocity profile can be brought into congruence by a simple scale factor. As a consequence, the dynamical equations are usually reduced to a single geometrical variable in their functional. The idea of self-similarity in fluid flows appears to have been applied for the first time by Blasius in 1908 for laminar boundary layers. Turbulent wakes are known to develop self-similarly downstream sufficiently far away from the obstacles that generate them (e.g. George 2012 and references therein). Some vortex wakes, whose longitudinal variables achieve similarity, can further be dependent on similarity conditions in the azimuthal direction too. The existence of similarity between axial and azimuthal velocity fields leads us in the current investigation to introduce the concept of helical self-preservation for turbulent vortex wakes.

As a starting point for our analysis of the interior of helical vortices, we employ the solution of the Lamb-Oseen vortex (Lamb 1932). This solution describes the decay of the azimuthal velocity $w$, or the associated vorticity distribution $\omega_{x}$, in a longitudinal vortex:

$$
\left.\begin{array}{c}
w(r, t)=\frac{\Gamma}{2 \pi r}\left(1-\exp \left(-\frac{r^{2}}{r_{c}^{2}(t)}\right)\right) \text { or } \\
\omega_{x}(r, t)=\frac{\Gamma}{\pi r_{c}(t)^{2}} \exp \left(-\frac{r^{2}}{r_{c}^{2}(t)}\right), \quad r_{c}(t)=\sqrt{4 t v_{k}},
\end{array}\right\}
$$


where $\Gamma$ is the vortex circulation, $r$ is the local radial coordinate from the centre of the vortex core, $r_{c}(t)$ is the radius of the vortex core and $v_{k}$ is the kinematic viscosity. A similar model was used by Ali \& Abid (2014) for comparison with results from Navier-Stokes simulations of helical vortices. In their comparison they proposed to use the radius growth of the Lamb-Oseen vortex

$$
\Delta r_{c}^{2} \equiv r_{c}^{2}(t)-r_{c}^{2}\left(t_{0}\right)=4\left(t-t_{0}\right) v_{k}
$$

as a model for the diffusion process of a helical vortex filament.

Another important element in our model is the concept of a two-dimension helical symmetry, proposed by Landman (1990) and Dritschel (1991). Assuming a helical vortex configuration consisting of a single vortex with constant pitch $(h=2 \pi l)$ and core radius $\left(r_{c}=\right.$ const.), the vorticity only depends on a single variable, $r$, and the relation between the axial and azimuthal vorticity components is given simply as the ratio between the radial position and the helical pitch:

$$
\omega_{x}=\frac{\Gamma}{\pi r^{2}} \exp \left(-\frac{r^{2}}{r_{c}^{2}}\right), \quad \omega_{\theta}=r \omega_{x} / l, \quad \omega_{r}=0 .
$$

A partial case of an axisymmetric flow with helical symmetry of the vorticity field (Kuibin \& Okulov 1996) is

$$
w=\frac{\Gamma}{2 \pi r}\left[1-\exp \left(-\frac{r^{2}}{r_{c}^{2}}\right)\right], \quad u=u_{0}-\frac{\Gamma}{2 \pi l}\left[1-\exp \left(-\frac{r^{2}}{r_{c}^{2}}\right)\right],
$$

where $u$ is the axial velocity component, $w$ is the tangential component and $u_{0}$ is the axial velocity at the centre of the vortex core. From (3.4) one gets a similar expression for the correlation between the velocities:

$$
u+\frac{r}{l} w=u_{0} .
$$

Using this expression, local helical symmetry for the average velocity has been found to exist in various swirling flow configurations (Martemianov \& Okulov 2004; Alekseenko et al. 2007; Velte et al. 2009).

At a first view, the velocity field in the form of (3.4) corresponds to the self-similar solution of the Batchelor vortex. For two trailing vortices located downstream from a wing, assuming that the core diameter is an order of magnitude smaller than the distance between the vortices, Batchelor (1964) proposed to replace the temporal dependence $t$ in the diffusion process (3.2) via a space correlation $x / B$

$$
\Delta r_{c}^{2} \equiv r_{c}^{2}(x)-r_{c}^{2}\left(x_{0}\right)=4\left(x-x_{0}\right) v_{t} / B,
$$

where $B$ is a characteristic velocity and $v_{t}$ is the turbulent viscosity, which may be identical to the one of the incoming turbulence flow. Batchelor furthermore derived the following form of the azimuthal and axial velocity components:

$$
r w(x, r)=C_{0}\left(1-e^{-\eta}\right), \quad u(x, r)=B-D e^{-\eta} / 8 \pi x v_{t},
$$

where $\eta=B r^{2} / 4 x v_{t}$, the constant $C_{0} \equiv \Gamma / 2 \pi$ represents $1 / 2 \pi$ times the flow circulation and $D$ describes the 'drag' of the body divided by density $\rho$. It should be mentioned that (3.7) originally was applied to an isolated longitudinal vortex. 
In order to apply (3.7) to helical vortices, the distance between the turns of the tip ${ }^{241}$ vortices is assumed to be large.

A universal solution including both helical symmetry and self-similar expansion of the vortex core is still unknown for longitudinal as well as for helical vortices, but as an empirical model together with (3.6), we propose a combination of (3.4) and (3.7) in the form

$$
w=\frac{\Gamma}{2 \pi r}\left[1-\exp \left(-\frac{r^{2}}{r_{c}^{2}(x)}\right)\right], \quad u=B-\frac{\Gamma}{2 \pi l(x)}\left[1-\exp \left(-\frac{r^{2}}{r_{c}^{2}(x)}\right)\right] . \quad(3.8 a, b) \quad{ }^{247}
$$

This new model only requires empirical knowledge or experimental calibration of some few flow parameters: vortex circulation, $\Gamma$, helical pitch, $l=l(x)$, advection velocity along the vortex axis, $B$, and growth factor of the vortex core, $r_{c}$. All the mentioned parameters can be determined experimentally by using PIV measurements of the velocity field (figure 3) together with the reconstructed vorticity field (figure 4).

The last images in figure 4 show a non-circular form of the vortex cores, which reveals the existence of an asymmetry of the global helix in a planar cross-section. By averaging the profiles, however, these asymmetric changes of the circular vortex core repeated from cross-section to cross-section have a marginal influence on the regular vortex evolution. The averaging is allowed by the linear correlation between the two velocities in (3.5). In accordance with this, azimuthally averaged local velocities and vorticity are used in the following:

$$
\left.\begin{array}{c}
\omega_{x}(x, r)=\frac{1}{2 \pi} \int_{0}^{2 \pi} \omega_{x}(x, r, \theta) \mathrm{d} \theta ; \quad w(x, r)=\frac{1}{2 \pi} \int_{0}^{2 \pi} w(x, r, \theta) \mathrm{d} \theta ; \\
u(x, r)=\frac{1}{2 \pi} \int_{0}^{2 \pi} u(x, r, \theta) \mathrm{d} \theta .
\end{array}\right\}
$$

248

The scaling radial similarity variable for the first, fourth and seventh vortex core (figure 4 ) is determined as the value of the radius, $r_{c}$. The value of $r_{c}$ is taken at the radius value where the azimuthal velocity $w$ attains its maximum. Therefore, the scaled values of the profiles (3.9) for a fixed axial position, $x$, or vortex number, can be recalculated by

$$
\left.\begin{array}{rl}
\tilde{\omega}_{x}\left(x, r / r_{c}(x)\right) & =\frac{\omega_{x}\left(x, r / r_{c}(x)\right)}{\max _{r} \omega_{x}(x, r)}, \\
\tilde{w}\left(x, r / r_{c}(x)\right) & =\frac{w\left(x, r / r_{c}(x)\right)}{\max _{r} w(x, r)}, \\
\tilde{u}_{d}\left(x, r / r_{c}(x)\right) & =\frac{u_{d}\left(x, r / r_{c}(x)\right)}{\max _{r} u_{d}(x, r)},
\end{array}\right\}
$$

where $\max _{r} u_{d}(x, r)$ requires a special consideration, as will be shown in the next ${ }_{268}$ section.

\section{Helical vortex development}

The evolution of the local cores of the helical tip vortices was investigated through velocity fields measured by stereoscopic PIV, as described in section 2 . Two global velocity plots with the blade oriented to the bottom at angles of $0^{\circ}$ and $105^{\circ}$ from the vertical axis were studied. The two cross-sections reproduce seven well-visible tip vortex cores, with the cores numbered by $1, \lambda^{\prime}, 4,4^{\prime}, 7$ and $7^{\prime}$, respectively, to keep 

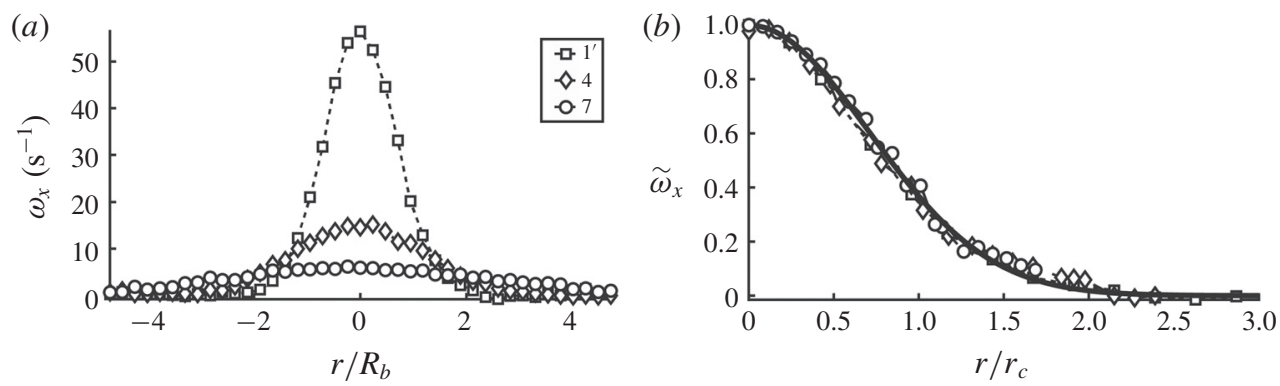

FIGURE 5. (a) Lines with symbols indicate the original PIV profiles of the local vorticity in the core at different cross-sections of the tested helical vortex. (b) Comparison of the same half profiles, scaled by (4.1), with the analytical non-dimensional solution (3.4) shown by a solid line.

$\begin{array}{lcccccc}\text { Number } & 1 & 1^{\prime} & 4 & 4^{\prime} & 7 & 7^{\prime} \\ \begin{array}{l}\text { Vortex age, s } \\ \begin{array}{l}\text { Distance along } \\ \text { global axis, } X / R_{b}\end{array}\end{array} & 0 & 0.13 & 0.46 & 0.59 & 0.92 & 1.05 \\ \begin{array}{l}\text { Turn angle, deg. (rad) } \\ \text { Length of vortex }\end{array} & 0(0) & 105(7 \pi / 12) & 360(2 \pi) & 465(31 \pi / 12) & 720(4 \pi) & 825(55 \pi / 12) \\ \text { central line, } x / R_{b} & 0 & 2.18 & 7.27 & 9.69 & 14.81 & 17.23\end{array}$

TABLE 1. Position of cross-sections of tip vortex cores.

track of the tip vortex trailed from the same blade (figure 4). The cross-sections may alternatively be described by the total angle they have travelled downstream, by their vortex age or by their axial position measured in rotor radii (see table 1).

The vortex age of a section of the tip vortex is calculated via the turn angles and the frequency of the rotor rotation, which for $\lambda=5$ is equal to $2.18 \mathrm{~Hz}$. The coordinate $x$ was calculated as in Quaranta et al. (2015). The intervals were selected to avoid any blade influence in the second core cross-section at the $105^{\circ}$ turn and to include the last vortex at the $825^{\circ}$ turn just before the helical vortex is destroyed. Indeed, the vortex core in the first position at $0^{\circ}$ near the rotor blade is strongly influenced by the rotor blade and the vortex generation process. In spite of this, for further analysis and to complete the picture, we have included both extreme positions ( 1 and $\left.7^{\prime}\right)$ in the analysis.

As a first step, a local coordinate system, $(x, r, \theta)$, with the origin located at the centre of each cross-section of the tested tip vortex was introduced. Examples of axial vorticity profiles at cross-sections $1^{\prime}, 4,7$, corrected for minor asymmetries by azimuthal averaging (3.9), are shown in figure $5(a)$. The same profiles scaled by (3.10) are shown in figure $5(b)$ and compared to the analytical solution (3.3). The scaling parameters of the investigated vorticity and velocity profiles are presented in table 2 .

As seen in figure 6, the circulation does not change along the tip vortex (figure $6 a$ ), whereas the evolution of the vortex core shows an expansion (figure $6 b$ ) that follows the law of molecular diffusion (3.6), but at a higher rate corresponding to a turbulent viscosity, which is about 2000 times higher than the molecular viscosity. The relative error for circulation and the vortex core radius was based on PIV velocity measuring 

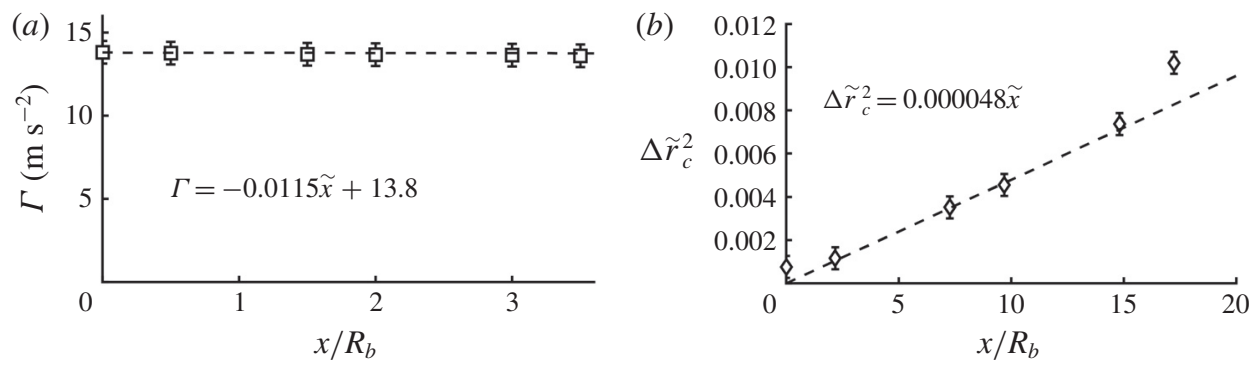

FIGURE 6. Downstream distribution of circulation (a) and evolution of vortex core radius (b) along the helical tip vortex in the different cross-sections. The lines are linear fittings.

$\begin{array}{lcccccc}\text { No. } & \max \omega_{x}, \mathrm{~s}^{-1} & r_{c}(x) / R_{b} & \Gamma, \mathrm{m}^{2} \mathrm{~s}^{-1} & u_{0}, \mathrm{~m} \mathrm{~s}^{-1} & l / R_{b} & \max u_{d}, \mathrm{~m} \mathrm{~s}^{-1} \\ 1 & 56.000 & 0.031 & 13.816 & -0.390 & 0.024 & 0.456 \\ 1^{\prime} & 50.000 & 0.037 & 13.760 & -0.330 & 0.044 & 0.330 \\ 4 & 22.600 & 0.061 & 13.692 & -0.220 & 0.084 & 0.217 \\ 4^{\prime} & 15.000 & 0.069 & 13.668 & -0.180 & 0.110 & 0.180 \\ 7 & 5.000 & 0.087 & 13.636 & -0.070 & 0.161 & 0.110 \\ 7^{\prime} & 4.000 & 0.102 & 13.600 & -0.060 & 0.185 & 0.095\end{array}$

TABLE 2. Parameters of the vortex evolutions.

error and was estimated to be $12 \%$ for the circulation and $10 \%$ for the vortex core radius. A suitable presentation of (3.6) gives the non-dimensional form of the solution:

$$
\Delta \tilde{r}_{c}^{2} \equiv \tilde{r}_{c}^{2}(x)-\tilde{r}_{c}^{2}\left(x_{0}\right)=4\left(\tilde{x}-\tilde{x}_{0}\right) / \operatorname{Re}_{T V},
$$

where $\tilde{r}_{c}=r_{c} / R_{b}, \tilde{x}=x / R_{b}$ and the turbulent Reynolds number $\operatorname{Re}_{T V}\left(\equiv B R_{b} / v_{t}\right)=8300$. The latter is related to the expansion of the tip vortex core and can be determined from the slope of the curve in figure $6(b)$. Deviations from the linear dependence in figure $6(b)$ take place only at the initial vortex cross-section 1 , on which the blade impacts, and on $7^{\prime}$, where the vortex loses coherence. The rate of the vortex core expansion coincides with the data of Quaranta et al. (2015), with minor deviations explained by the different blade designs and the influence of walls in their experiments.

There is no direct correlation between the local velocity field $(u, v, w)$ and the measured components of the velocity $(U, V, W)$, as the velocity field in the vortex core is superposed by the motion of the helical vortex. To determine the local velocity distribution in the $(r, \theta)$ plane of the vortex core, the transport velocity of the centre of the vortices was measured and subtracted from the total velocity of each cross-section.

Figure $7(a)$ shows the local azimuthal velocity $w$ in cross-sections $1^{\prime}, 4,7$ after removal of the transport velocity and azimuthal averaging. The scaling by (3.10) of the profiles clearly indicates the existence of self-similarity of the local azimuthal velocity inside the tip vortex (figure $7 b$ ). These velocity profiles show a slight difference as compared to the non-dimensional self-similarity solutions (3.8) with the Gaussian core reproduced by the data in table 2. This difference is most likely due to wall effects, which generate a swirling flow (Alekseenko et al. 2007) that creates an additional vorticity surrounding the original vortex core. The experiments 

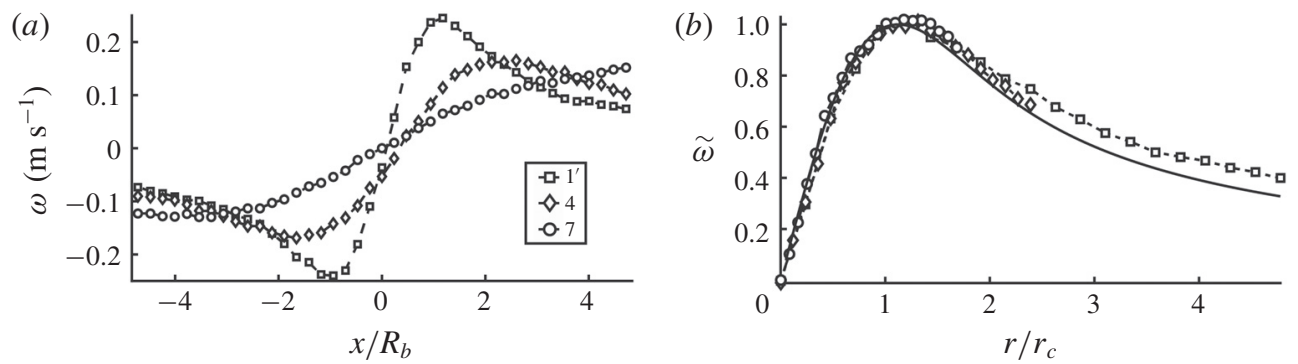

FIGURE 7. (a) Lines with symbols are the original PIV profiles of the local azimuthal velocity in the different cross-sections of the tip helical vortex. (b) The self-similar behaviour of the same profiles scaled by (4.1). The full line is the dimensionless Gaussian solution (3.9).
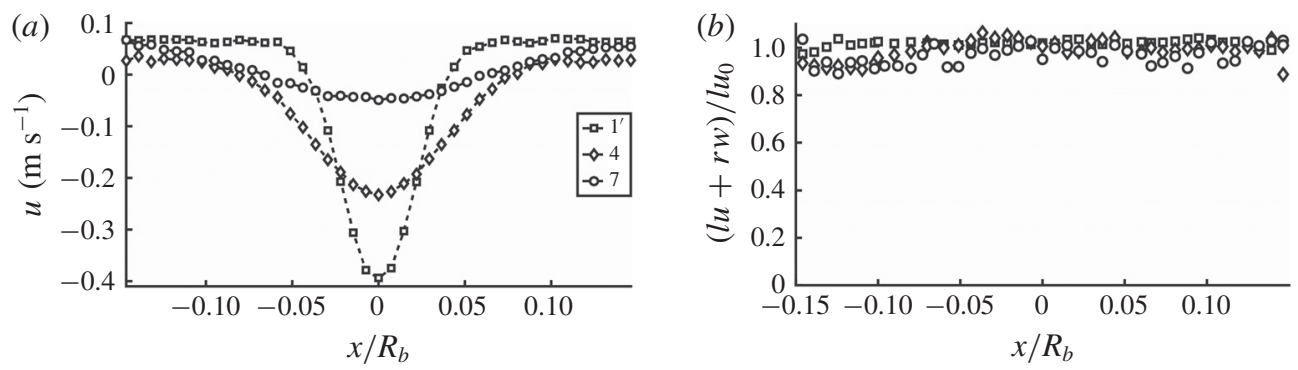

FIGURE 8. (a) Lines with symbols are the original PIV profiles of the local axial velocity in the different cross-sections of the tip vortex. (b) Symbols show the correlations between the local azimuthal and axial velocities, using (3.5) to identify the pitch $l$.

of Quaranta et al. (2015) revealed large deviations from a Gaussian vortex, which can be explained by wall effects, as the rotor in their experiments was located less than a rotor diameter from the wall.

Figure 8(a) shows the local axial velocity $u$ extracted directly from the global azimuthal velocity $W^{*}$. A small total wake rotation exists due to the hub vortex generated in the centre of the rotor wake, which gives rise to a negative overshoot of the local axial velocity profiles (figure $8 a$ ). This, however, vanishes further downstream in the wake. A visual demonstration of the existence of a local axial motion in the centre of the tip vortex was given by Quaranta et al. (2015) using dye injections in the core of the tip vortex. This axial motion is generated by the local structure of the helical vortex lines of the tip vortices (figure 1c). However, the existence of an ambient wake rotation with an unknown velocity $W^{*}\left(X^{*}, Y^{*}, Z^{*}\right)$ does not permit a solid conclusion regarding the actual size of the local axial velocity deficit $B=W^{*}-u_{0}$. Indeed, only $u_{0}=u(x, 0)$ can be determined directly from the profiles in figure $8(a)$. This problem can be avoided if the core of the helical vortex has a local helical structure consisting of local vortex lines (figure 1c). In this case, the local helical symmetry condition (3.5) between axial and azimuthal velocities can be exploited with an acceptable accuracy, which only depends on measurement errors and disturbances from the surrounding helical vortices (including the turns of the investigated vortex). Furthermore, the linear velocity formulation for local helical symmetry (3.5) allows the usage of averaged velocity fields (3.9) to determine the 

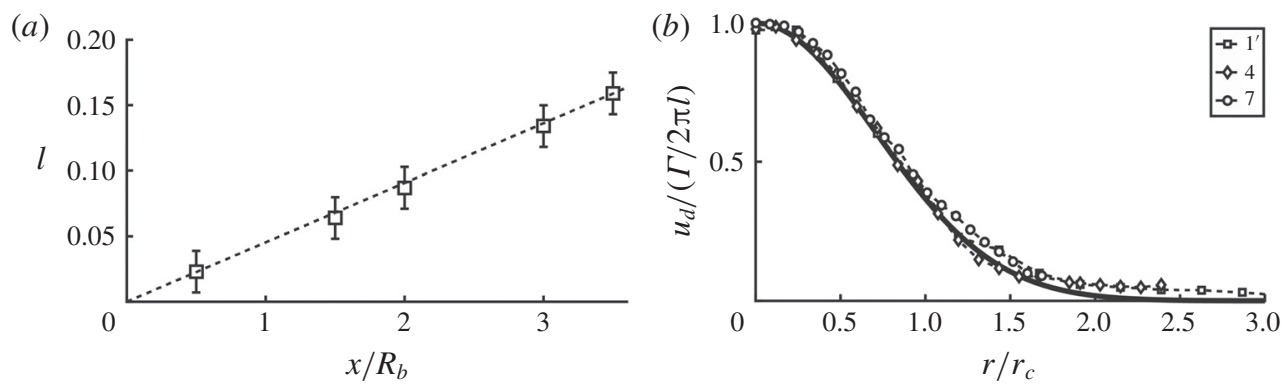

FIgURE 9. (a) Evolution of the local helical pitch. (b) The self-similarity behaviour of the axial velocity deficit in the tip vortex core scaled by (4.1). The solid line is the nondimensional velocity deficit with the Gaussian core (3.9).

helical vortex characteristics. The good correlation of the velocity profiles (figure $8 b$ ) in accordance with the formula (3.5) permits one to conclude the existence of a local helical structure of the tip vortex core. Furthermore, it gives the values of the pitch $l$ of the local helical symmetry (figure $9(a)$ and table 2). The relative error of the helical pitch $l$ was estimated to be about $10 \%$.

As a next step, we transform the original local axial velocity profiles (figure $8 a$ ) into the form $u_{d}(x, r)=\left[u(x, r)-u_{0}(x)\right]$. In order to assess the similarity of the deficit profiles, the profiles are scaled with $\Gamma / 2 \pi l$. This result is shown in figure $9(b)$ where the deficit velocity, made dimensionless by $\Gamma / 2 \pi l$, depends inversely on the axial distance $(1 / x)$, as indicated by the self-similar solution (3.8). The comparisons clearly indicate that the local flow distribution in the tip vortex core is Gaussian and that it exhibits helical self-similarly.

\section{Conclusions}

Helical tip vortices generated by a three-bladed rotor were measured using stereoscopic PIV measurements in a water flume, with the aim of investigating possible self-similarity of the velocity profiles in the vortex core. The data were analysed and processed assuming different self-similarity scaling arguments. Both the local azimuthal vorticity profiles and the local axial and azimuthal velocity components were investigated and showed the existence of helical self-similarity, which is well described by the proposed model (3.8) and (4.1). Furthermore, a good correlation existed between measurements and vortex flow decay using Batchelor's vortex $((3.6)$ and $(3.7 a, b))$ with a Gaussian vortex core. The proposed helical self-similarity scaling arguments enable further investigations of, for example, the stability of helical vortex cores, where expressions of full velocity profiles along the vortex axis are required. The proposed model was developed and tested for flows close to the design operating condition of the wind turbine, where a clearly defined vortex structure is formed. However, at flow conditions where the regular vortex structure is destroyed by external disturbances, or at extreme off-design operating conditions, the validity of the model may be questionable. A study of the limitations of the model will be the subject for future work.

The achieved knowledge is important for the fundamental understanding of vortex flows as well as for different practical applications in which the parametric description requires the use of simplified analytical engineering expressions. Examples of this are tip vortices behind aerodynamic devices, such as vortex generators, and fixed and rotary aircraft, and in combustion chambers and cyclone separators. 


\title{
Acknowledgement
}

The research was supported by the RSF (Project no. 14-19-00487).

\author{
REFERENCES
}

Alekseenko, S. V., Kuibin, P. A. \& OKulov, V. L. 2007 Theory of Concentrated Vortices: An Introduction. Springer Science \& Business Media.

ALI, M. \& ABID, M. 2014 Self-similar behaviour of a rotor wake vortex core. J. Fluid Mech. 740 (R1), 1-11.

Batchelor, G. 1964 Axial flow in trailing line vortices. J. Fluid Mech. 20 (4), 645-658.

Dritschel, D. G. 1991 Generalized helical Beltrami flows in hydrodynamics and magnetohydrodynamics. J. Fluid Mech. 222, 525-541.

Felli, M., Camussi, R. \& Di Felice, F. 2011 Mechanisms of evolution of the propeller wake in the transition and far fields. J. Fluid Mech. 682, 5-53.

Fukumoto, Y. \& MiYAZAKI, T. 1991 Three-dimensional distortions of a vortex filament with axial velocity. J. Fluid Mech. 222, 369-416.

GeORGE, W. K. 2012 Asymptotic effect of initial and upstream conditions on turbulence. Trans. ASME J. Fluids Engng 134 (6), 061203.

Gupta, B. P. \& LOEWY, R. G. 1974 Theoretical analysis of the aerodynamics stability of multiple, interdigitated helical vortices. AIAA J. 12, 1381-1387.

Kuibin, P. A. \& OKulov, V. L. 1996 One-dimensional solutions for a flow with a helical symmetry. Thermophys. Aeromech. 3 (4), 335-339.

LAMB, H. 1932 Hydrodynamics. Cambridge University Press.

LANDman, M. J. 1990 On the generation of helical waves in circular pipe flow. Phys. Fluids A 2, 738-747.

Leishman, J. G. 2006 Principles of Helicopter Aerodynamics. Cambridge University Press.

Martemianov, S. \& OKUlov, V. L. 2004 On heat transfer enhancement in swirl pipe flows. Intl J. Heat Mass Transfer 47, 2379-2393.

Naumov, I. V., Mikkelsen, R. F., Okulov, V. L. \& Sørensen, J. N. 2014 PIV and LDA measurements of the wake behind a wind turbine model. J. Phys.: Conf. Ser. 524 (1), 012168.

Naumov, I. V., Rahmanov, V. V., Okulov, V. L., Velte, C. M., Meyer, K. E. \& Mikkelsen, R. F. 2012 Flow diagnostics downstream of a tribladed rotor model. Thermophys. Aeromech. 19 (2), 171-181.

Okulov, V. L., Mikkelsen, R., Litvinov, I. V. \& Naumov, I. V. 2015 a Efficiency of operation of wind turbine rotors optimized by the Glauert and Betz methods. Tech. Phys. 60 (11), $1632-1636$.

Okulov, V. L., Naumov, I. V., Mikkelsen, R. F., Kabardin, I. K. \& Sørensen, J. N. 2014 A regular Strouhal number for large-scale instability in the far wake of a rotor. J. Fluid Mech. 747, 369-380.

OKulov, V. L. \& SøRensen, J. N. 2010 Maximum efficiency of wind turbine rotors using Joukowsky and Betz approaches. J. Fluid Mech. 649, 497-508.

OKulov, V. L., Sørensen, J. N. \& Wood, D. H. $2015 b$ The rotor theories by Professor Joukowsky: vortex theories. Prog. Aerosp. Sci. 73, 19-46.

Quaranta, H. U., Bolnot, H. \& Leweke, T. 2015 Long-wave instability of a helical vortex. J. Fluid Mech. 780, 687-716.

Saffman, P. G. 1992 Vortex Dynamics, p. 252. Cambridge University Press.

Selig, M. S., Guglielmo, J. J., Broeren, A. P. \& Giguere, P. 1995 Summary of low-speed airfoil data. In Solar Tech. Publication, vol. 1, p. 292.

Sørensen, J. N. 2011 Instability of helical tip vortices in rotor wakes. J. Fluid Mech. 682, 1-4.

Sørensen, J. N., Mikkelsen, R., Sarmast, S., Ivanell, S. \& Henningson, D. 2014 Determination of wind turbine near-wake length based on stability analysis. J. Phys.: Conf. Ser. 524, 012155. 
Sørensen, J. N., Okulov, V. L., Mikkelsen, R. F., Naumov, I. V. \& Litvinov, I. V. 2016 Comparison of classical methods for blade design and the influence of tip correction on rotor performance. J. Phys.: Conf. Ser. 753 (2), 022020.

Sørensen, J. N. \& Shen, W. Z. 2002 Numerical modelling of wind turbine wakes. Trans. ASME J. Fluids Engng 124 (2), 393-399.

Van Kuik, G. A. M., Sørensen, J. N. \& Okulov, V. L. 2015 Rotor theories by Professor Joukowsky: momentum theories. Prog. Aerosp. Sci. 73, 1-18.

Velte, C. M., Hansen, M. O. L.\& OKulov, V. L. 2009 Helical structure of longitudinal vortices embedded in turbulent wall-bounded flow. J. Fluid Mech. 619, 167-177.

Vermeer, L. J., Sørensen, J. N. \& Crespo, A. 2003 Wind turbine wake aerodynamics. Prog. Aerosp. Sci. 39, 467-510.

Widnall, S. E. 1972 The stability of a helical vortex filament. J. Fluid Mech. 54, 641-663. 
Please do not answer on this page but find the appropriate point in the text and make your annotation there.

\section{Author Queries}

Journal: $\quad$ FLM

Article id: 00850

Author: $\quad$ V. L. Okulov and others

Short title: Helical self-similarity of tip vortex cores

Q1 (Page 1)

$\mathrm{Au}$ : The distinction between surnames can be ambiguous, therefore to ensure accurate tagging for indexing purposes online (eg for PubMed entries), please check that the highlighted surnames have been correctly identified, that all names are in the correct order and spelt correctly.

Q2 (Page 1)

$\mathrm{Au}$ : Please check that the affiliations are correct for all authors. Also please ensure that department, institution, town, postal code and country are included if missing.

Q3 (Page 1)

Au: As per journal style only 1-3 key words are required. Please retain up to three. Key words must be selected from the list available at http://journals.cambridge.org/data/relatedlink/jfm-keywords.pdf

Q4 (Page 2)

Au: Sarmast et al. (2015) cited here but not in reference list. Please provide the reference or remove from citation.

Q5 (Page 13)

Au: Okulov et al.(2015b): not cited in text. Please cite inside text or remove from the reference list.

Q6 (Page 13)

Au: Selig et al. (1995): please provide publisher name. 